\title{
Identification and Adaptive Fuzzy Control for Navigation Systems of Autonomous Vehicles
}

\begin{abstract}
Julián Arbeláez ${ }^{6}$

This article presents a simple method to generate the automatic course control of surface naval vehicles by using fuzzy logic to adjust the parameters of the PID controller. The fuzzy systems constructed to automatically adapt the parameters of the PID controller are Mamdani type and use functions of triangular relevance for the antecedent and the consequent. An application to a real model is presented, exposing the identification process to obtain the mathematical model from experimental data, the temporal analysis from the mathematical model, obtain the parameters from the PI controller, and the results on course changes between $125^{\circ}$ and $305^{\circ}$. Thereafter, and bearing in mind the range of Kp and Ti parameters in which the system is stable, a structure of a self-tunable fuzzy PI controller was presented and implemented with notable improvement in the response system.
\end{abstract}

Juan Contreras ${ }^{1}$

Manuel Ariza ${ }^{2}$

Luís Velásquez ${ }^{3}$

Alcides Ramos ${ }^{4}$

Vladimir Díaz ${ }^{5}$

Key words: identification, root locus, PID control, fuzzy PI control, self-tuning

\section{Resumen}

Este artículo presenta un método sencillo para la generación del control automático del rumbo de vehículos navales de superficie empleando la lógica difusa para ajustar los parámetros del controlador PID. El sistema difuso construido para adaptar automáticamente los parámetros del controlador PID es del tipo Mamdani y emplea funciones de pertenencia triangulares para el antecedente y el consecuente. Se presenta una aplicación a un modelo real, exponiendo el proceso de identificación para la obtención del modelo matemático a partir de datos experimentales, el análisis temporal del modelo matemático, la obtención de los parámetros del controlador PI, y los resultados ante cambios de rumbo entre $125^{\circ} \mathrm{y}$ $305^{\circ}$. Posteriormente, y teniendo en cuenta el rango de los parámetros Kp y Ti en que el sistema es estable, se presentó e implementó una estructura de un controlador PI difuso autosintonizable con una mejora notable en la respuesta del sistema.

Palabras claves: identificación, lugar de las raíces, control PID, control PI difuso, autosintonización

Date Received: December 13th, 2012 - Fecha de recepción: 13 de Diciembre de 2012

Date Accepted: February 19th, 2013 - Fecha de aceptación: 19 de Febrero de 2013

\footnotetext{
${ }^{1}$ Faculty of Naval Engineering - Escuela Naval Almirante Padilla, Cartagena de Indias, Colombia. e-mail: epcontrerasj@ieee.org

${ }^{2}$ Faculty of Naval Engineering - Escuela Naval Almirante Padilla, Cartagena de Indias, Colombia. e-mail: amatgwill@hotmail.com

${ }^{3}$ Faculty of Naval Engineering - Escuela Naval Almirante Padilla, Cartagena de Indias, Colombia. e-mail: jdesem@gmail.com

${ }^{4}$ Faculty of Naval Engineering - Escuela Naval Almirante Padilla, Cartagena de Indias, Colombia. e-mail: alcidesramos@yahoo.es

${ }^{5}$ COTECMAR. Research, Development, and Innovation Department. Cartagena, Colombia. e-mail: vdiaz@cotecmar.com

${ }^{6}$ Faculty of Naval Engineering - Escuela Naval Almirante Padilla, Cartagena de Indias, Colombia. e-mail: yeha8040@hotmail.com
} 


\section{Introduction}

An autopilot is one of the most important devices on board a ship; it is connected to its governor system and makes course corrections based on information from the compass, GPS, and digital compass, among other sensors. An autopilot with adaptable parameters and optimization techniques incorporated can contribute to maintaining or following a desired course in such an efficient manner that it can reduce the route by up to $5 \%$, thus, also reducing fuel consumption (Witkowska and Smierzchalski, 2008; Krishna et al., 2011).

The Proportional-Integral-Derivative (PID) control technique has been widely used in autopilots because of its simplicity and ease of implementation. However, the performance of PID controllers has not shown good results in the changing environmental conditions that can be encountered by the ship in its navigation route (Nguyen et al., 2003; Loo and Mastorakis, 2007).

To design the course controller, it is necessary to have a mathematical model that describes, as closely as possible, the ship's dynamics. The motion of the ship at sea is described by a set of six complicated differential equations related to its six degrees of freedom (Tzeng and Chen, 1999; Fossen, 2002). However, it is a common practice to consider only the horizontal plane, which is why the degrees of freedom are reduced to three and, thereby, the mathematical model is simplified (Krishna et al., 2011). One of the most used models for the preliminary design of the course controller is the Nomoto model (Velazco et al., 2008; Chang et al., 2010; Krishna et al., 2011) due to its simplicity.

Fuzzy logic has turned out to be a very effective technique to overcome inconveniences presented by PID control, permitting the generation of fuzzy controllers with great adaptation capacity. In some cases, it is used as automatic adjustment mechanism (selftuning) of PID controller parameters (Velagic et al., 2003; Nguyen et al., 2003; Loo et al., 2007; Contreras, 2011; Contreras et al., 2011).

This article is organized as follows. Section 2 presents a brief description of the scale model (surface vehicle) used during the identification and control tests; Section 3 describes the identification process used to obtain the mathematical model of the surface vehicle; Section 4 analyzes the temporal behavior of the mathematical model obtained and proceeds to calculate the parameters of the PID controller; Section 5 gives the structure of the self-tunable fuzzy PI controller and the results obtained, followed by the conclusions.

\section{Description of the scale model}

The surface vehicle used belongs to the Almirante Padilla Naval School, located in Cartagena, Colombia, and has a wooden hull, with a length of $0.78 \mathrm{~m}$ and a $0.22-\mathrm{m}$ breadth. The dimensions of the model are presented in Table I and Fig. 1.

Table 1. Characteristics of the surface model

\begin{tabular}{lr}
\hline \multicolumn{1}{c}{ Item } & \multicolumn{1}{c}{ Description } \\
\hline Length & $0.78 \mathrm{~m}$ \\
\hline Breadth & $0.22 \mathrm{~m}$ \\
\hline Depth & 0.15 \\
\hline Weight & $9.2 \mathrm{Kg}$ \\
\hline Propelling source & DC $\mathrm{motor}$ \\
\hline Autonomy & $1.2 \mathrm{~h}$ \\
\hline Maximum velocity & $1.3 \mathrm{~m} / \mathrm{s}$ \\
\hline
\end{tabular}

Fig. 1. Surface vehicle used

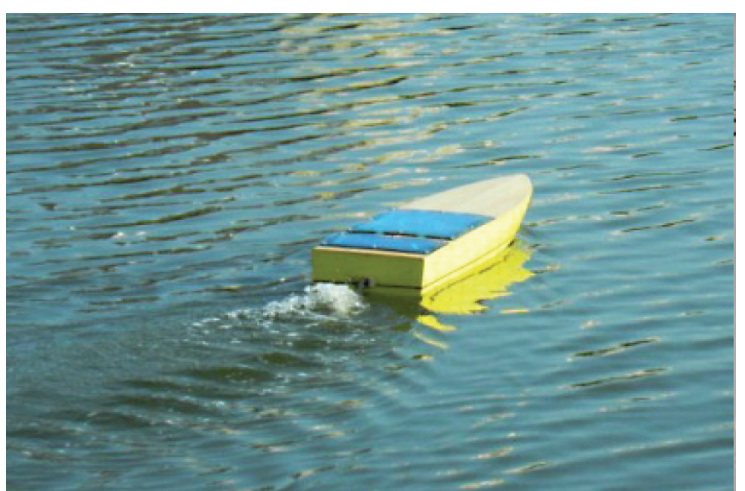


b) Version with vision and sonar system

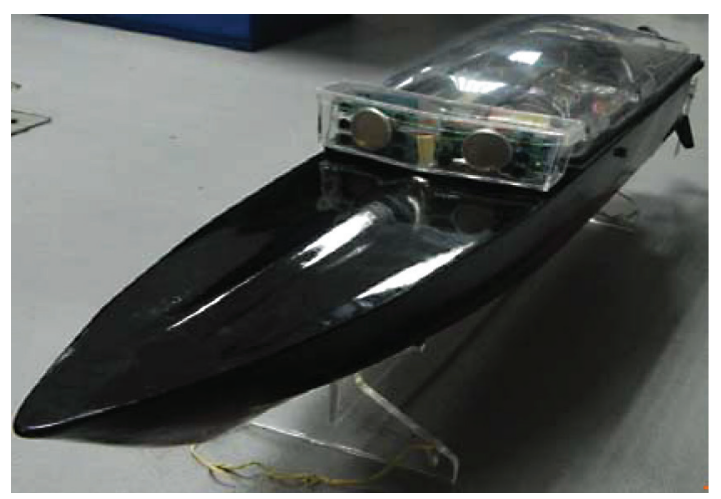

The surface vehicle contains, among others, the following elements on board: electronic compass, GPS; accelerometers, propulsion motors, servomotors and rudder system, sonar, video camera, and RF communication module.

\section{Identification of the Dynamics of the Surface Model}

Fig. 2. Variables defining the ship's course

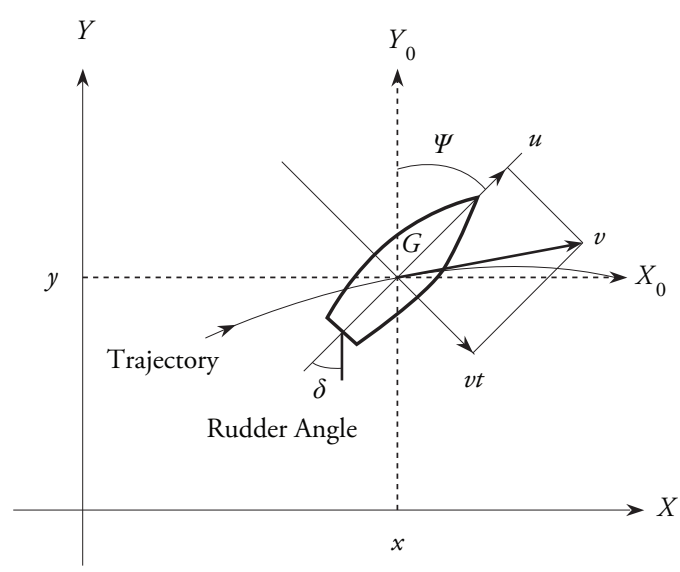

A simple model describing the dynamic behavior of a ship can be expressed through Nomoto's third-order model (Tzeng and Chen, 1999; Du and Guo, 2004):

$$
\begin{aligned}
\dddot{\psi}(t)+\left(\frac{1}{T_{1}}+\frac{1}{T_{2}}\right) \ddot{\psi}(t) & +\frac{1}{T_{1} T_{2}} H_{N}(\dot{\psi}(t)) \\
& =\frac{K}{T_{1} T_{2}}\left(T_{3} \delta(t)+\delta(t)\right)
\end{aligned}
$$

where $\Psi(t)$ is the course angle and $\delta(t)$ is the rudder angle. If we assume initial conditions null, the Nomoto equation can be represented in the Laplace domain through the following transference function:

$$
\frac{\psi(s)}{\delta(s)}=\frac{K\left(T_{3} s+1\right)}{s\left(T_{1} 2+1\right)\left(T_{2} s+1\right)}
$$

The prior equation could be obtained through identification techniques using experimental data and selecting one of the structures of models included in the IDET identification tool by MATLAB (arx, armax, oe, etc.) that best approaches the dynamics represented by the experimental data.

To identify the course a maneuver similar to the zig-zag curve was used, varying the rudder angle between $20^{\circ}$ and $-20^{\circ}$ (Fig. 3), which causes course changes of the physical model to port and starboard. The platform maintains approximately constant velocity during the whole maneuver. Several tests were conducted in the Bay of Cartagena de Indias, in El Laguito sector, seeking to obtain a mathematical model with enough precision to proceed to design the course control system.

We sought to obtain a low-order model, but due to the delay presented by the model's response it was not possible to reach a second-order model that permitted an analogy of the coefficients with the structure of the model by Nomoto. The best model was obtained with the AutoRegressive Moving Average eXogen (ARMAX) structure, whose discrete time representation is shown by the following:

$$
\frac{\psi(s)}{\delta(s)}=\frac{0.02347}{z^{4}-1.29 z^{3}+0.2897 z^{2}}
$$

In continuous time:

$\frac{\psi(s)}{\delta(s)}=\frac{0.009098 s^{4}-1.213 s^{3}+60.65 s^{2}-1348 s+11230}{s^{4}-85.02 s^{3}+2553 s^{2}+20390 s-137.6}$

The mean quadratic error achieved was 1.2446e+003. Fig. 4 shows the comparison between the real course real and the output of the ARMAX model. 
Fig. 3. Data taken from the surface model identification experiment

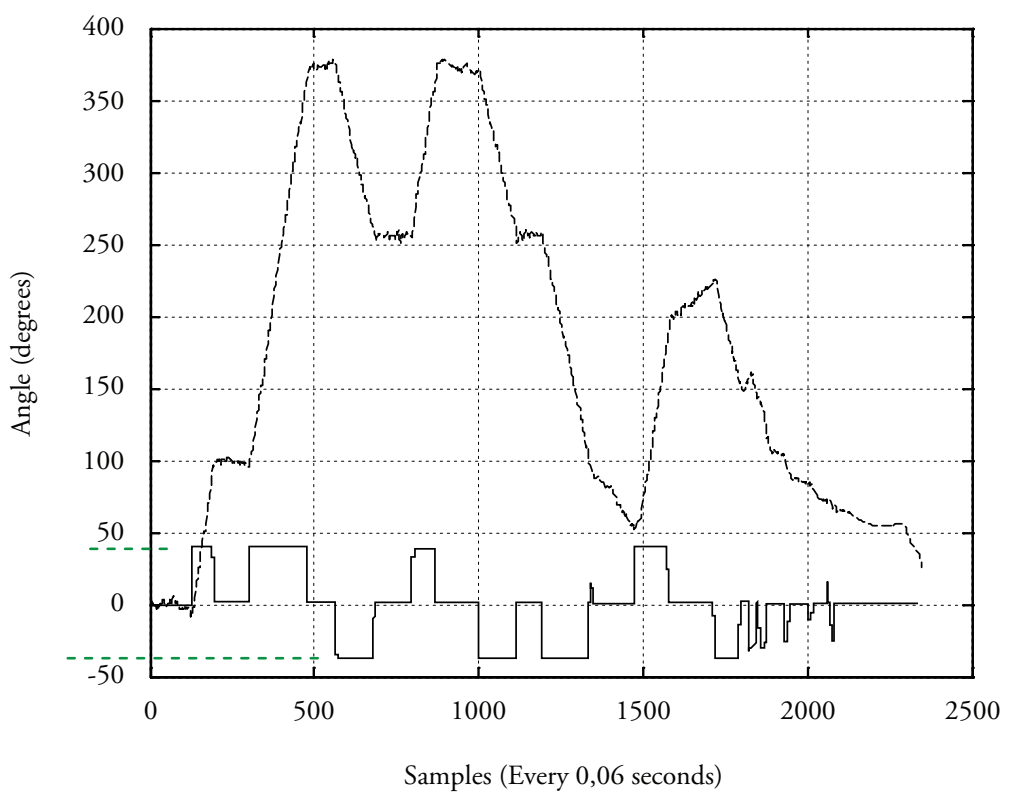

Fig. 4. Comparison between the vehicle's real response and the response of the ARMAX mathematical model on rudder angle variation

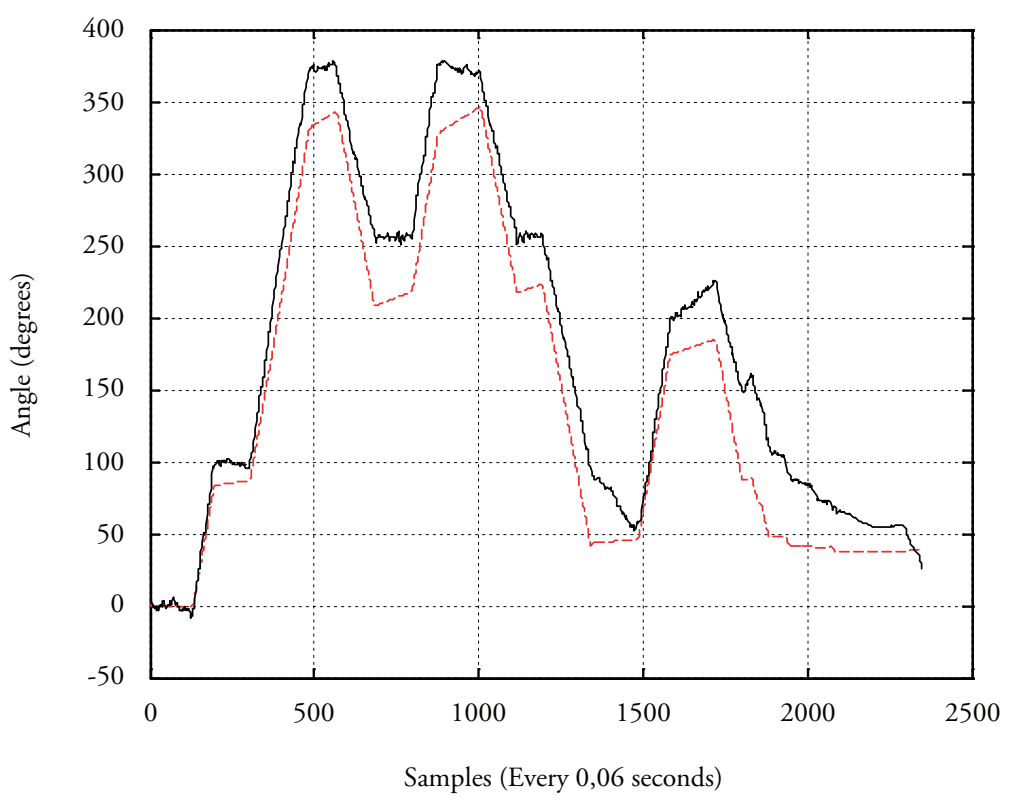

The mathematical model obtained is of fourth can have damped oscillations in its response (as order, with a pole close to the origin $(s 1=0.0067), \quad$ long as it is taken out of the instability zone).

but on the positive side of the complex $S$ plane, which indicates a tendency to instability. It presents a pole on the real negative axis $(s 2=-18.3478)$ and two complex poles conjugated with real negative part $(\mathrm{s} 3=-33.3394+\mathrm{j} 0.7993 ; \mathrm{s} 4=-33.3394-$ j0.7993), which give an indication that the system

\section{Design of the Pid Controller}

After obtaining the mathematical model, we proceeded to design a PID controller to regulate 
the course of the surface vehicle. The first step was to obtain the system's Root locus (vehicle) to know its temporal behavior (Fig. 5).

The Root locus shows that the system has a pole that at low system gain is located near the origin but on the positive side of the $S$ plane, which generates unstable behavior. This pole can be displaced to the left side of the $S$ plane if the system's closed loop gain is greater than 0.0153 . If the closed loop gain increases above 90, the system will again fall in instability. For the closed loop gain of 90, the system will have a critically stable behavior, which permits applying the Ziegler - Nichols method to design the PID controller.

Fig. 6 shows the application of a gain variable to the system to determine the critical gain, Kcr, which would bring the system to the critically stable state.

Fig. 5. Root locus of the surface vehicle model

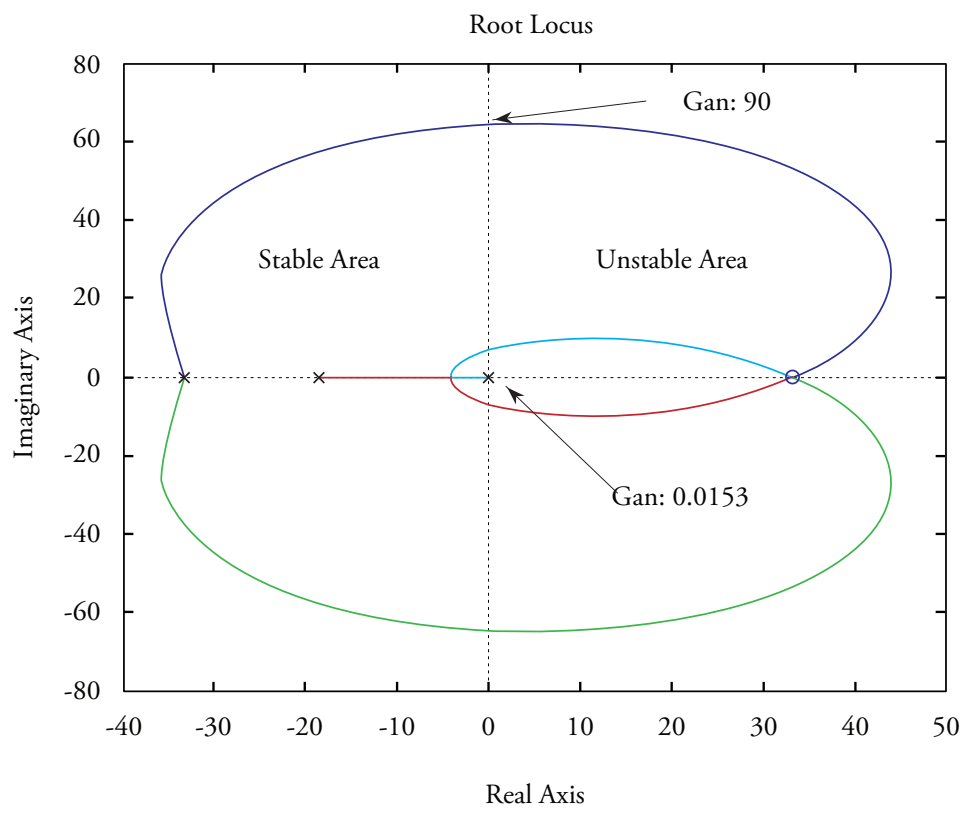

Fig. 6. Scheme to determine the critical gain, Kcr

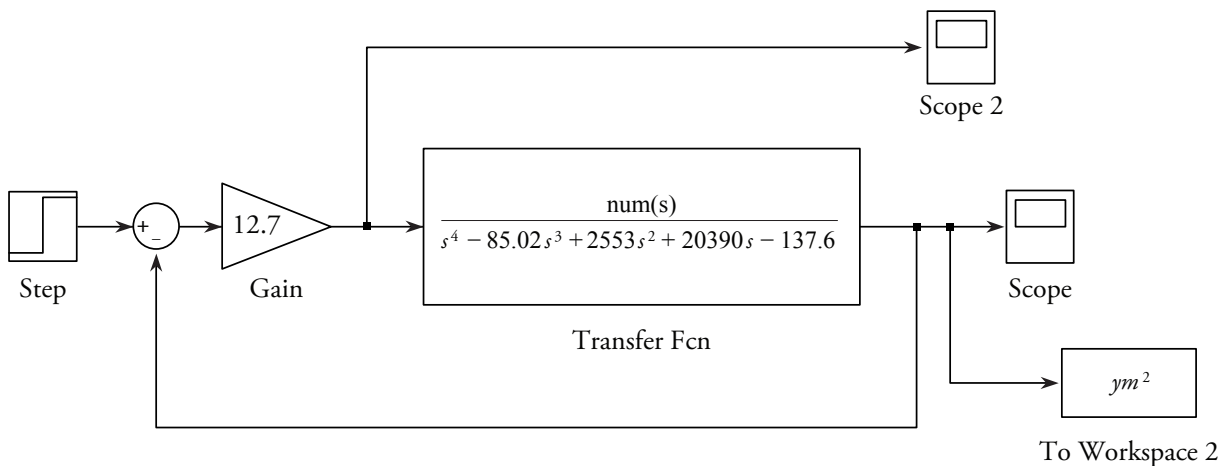

The value of $\mathrm{Kcr}$ is 12.7. The critical period is obtained from Fig. 7. The critical period, Pcr, is 0.93 seconds. With Table 2. the value of the critical gain, Kcr, value of 12.7 , we proceeded to seek the controller parameters in 
Fig. 7. Critical period, Pcr, obtained

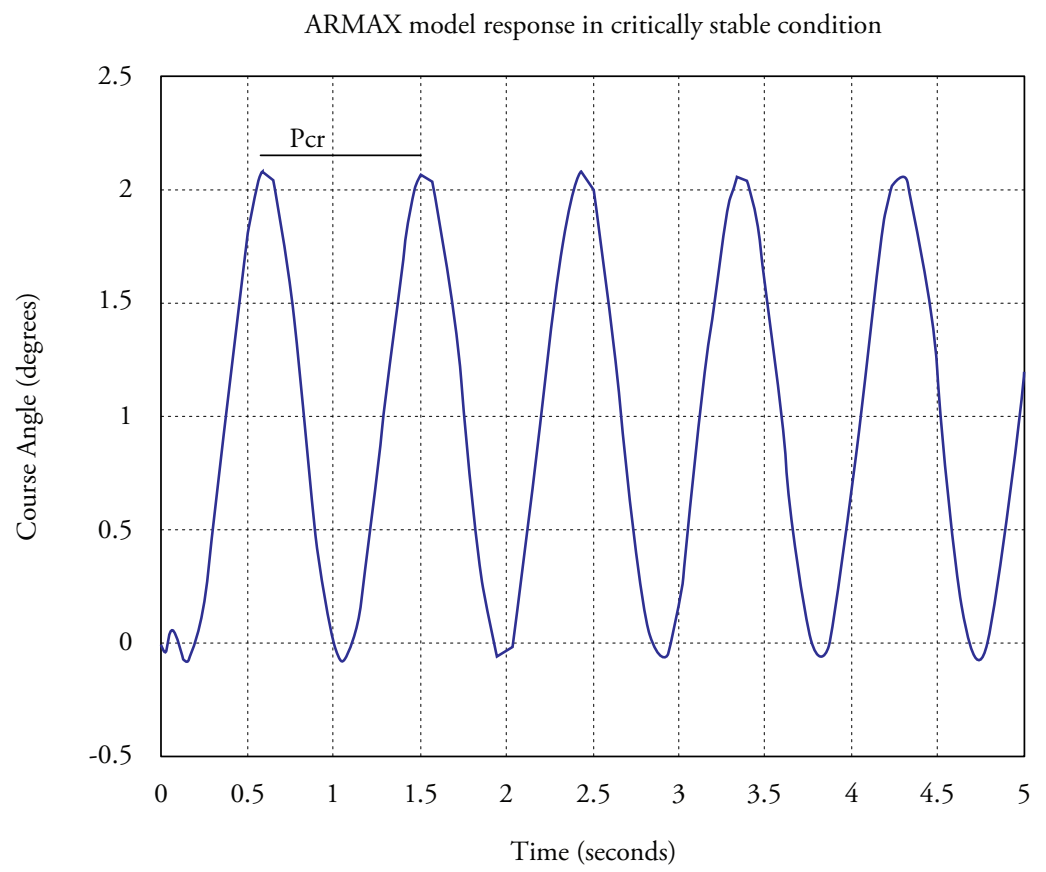

Table 2. Ziegler - Nichols' second method

\begin{tabular}{|c|c|c|c|}
\hline $\begin{array}{c}\text { Type of } \\
\text { Controller }\end{array}$ & Kp & Ti & Td \\
\hline $\mathbf{P}$ & $0.5 \mathrm{Krc}$ & $\infty$ & 0 \\
\hline PI & $0.5 \mathrm{Krc}$ & 1/1.2 Pcr & 0 \\
\hline PID & $0.6 \mathrm{Krc}$ & $0.5 \mathrm{Pcr}$ & $0.125 \mathrm{Pcr}$ \\
\hline
\end{tabular}

That is, to obtain the PI controller, the parameters will be:

$$
\begin{aligned}
& \mathrm{Kp}=0.5^{*} \mathrm{Kcr}=0.5^{*} 12.7=6.35 \\
& \mathrm{Ti}=\mathrm{Pcr} / 1.2=0.93 / 1.2=0.775
\end{aligned}
$$

It should be noted that the SIMULINK PID equation differs from the conventional equation, thus:

Conventional equation of the PID:

$$
\mathrm{u}(\mathrm{t})=\mathrm{Kp}[1+1 / \mathrm{Ti}+\mathrm{Td}]^{*} \mathrm{e}(\mathrm{t})
$$

SIMULINK PID equation:

$$
u(t)=[P+I+D]^{*} e(t)
$$

That is, $\mathrm{Kp}=\mathrm{P} ; \mathrm{I}=\mathrm{Kp} / \mathrm{Ti} ; \mathrm{D}=\mathrm{Kp}{ }^{*} \mathrm{Td}$. Hence, for the SIMULINK simulation use $\mathrm{P}=6.35$ and $\mathrm{I}=$ $6.35 / 0.775=8.19$

The system response with PID controller upon a 20-degree reference signal is shown in Fig. 8.

An error is reached in stationary state equal to zero; however, the over impulse is high. The results obtained in the tests on the prototype resulted with a higher over impulse due to delay in controller data transmission from the PC.

The proportional gain was adjusted to diminish over impulse and a better response was obtained with $\mathrm{P}=3$ (Fig. 9).

The results of the vehicle's real response to reference signal changes (desired course) from $300^{\circ}$ to $125^{\circ}$, regulated with the PI controller, are shown in Fig. 10.

The real system response, shown in Fig. 10, presents oscillations, especially when the course 
Fig. 8. Response of the controlled model $(\mathrm{P}=6.35$ and $\mathrm{I}=8.19)$ on course change request from $0^{\circ}$ to $20^{\circ}$

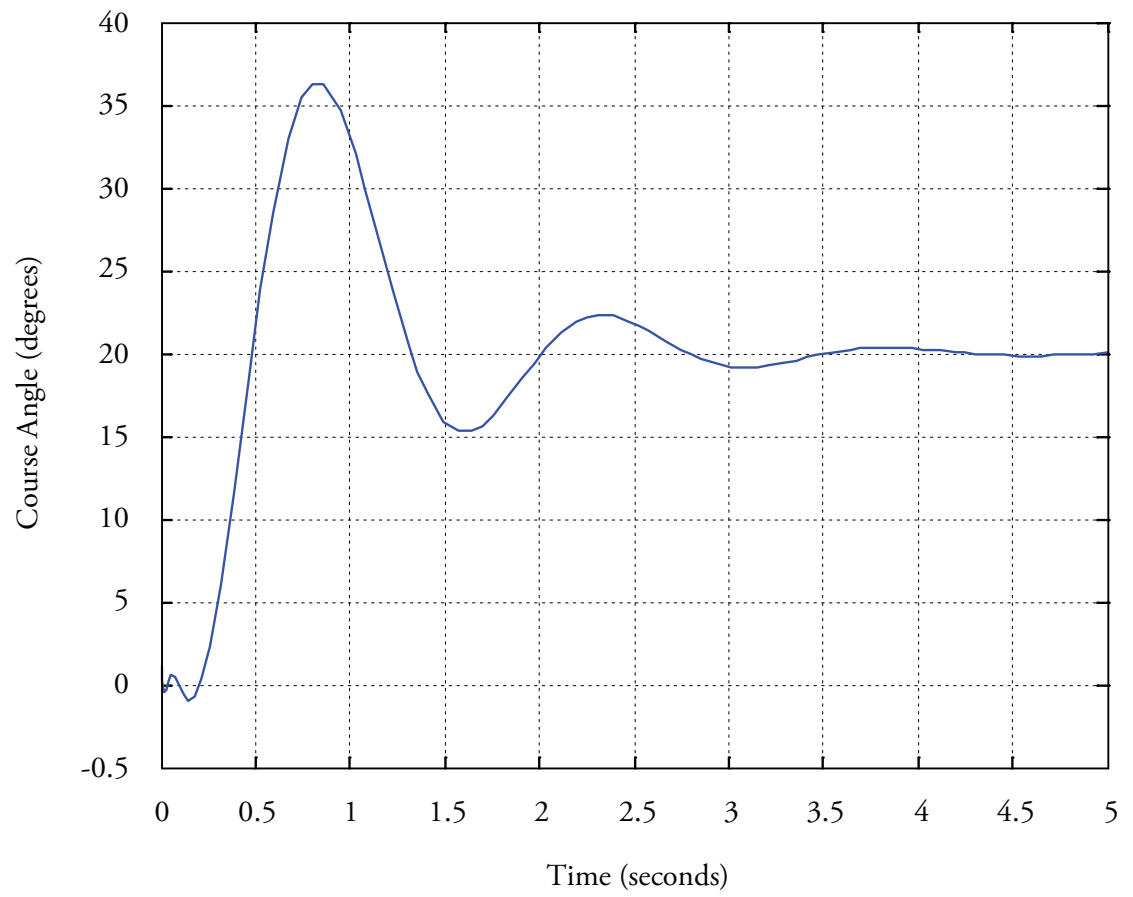

Fig. 9. Response of the controlled model $(\mathrm{P}=3$ and $\mathrm{I}=8.19)$ upon change of course request from $0^{\circ}$ to $20^{\circ}$

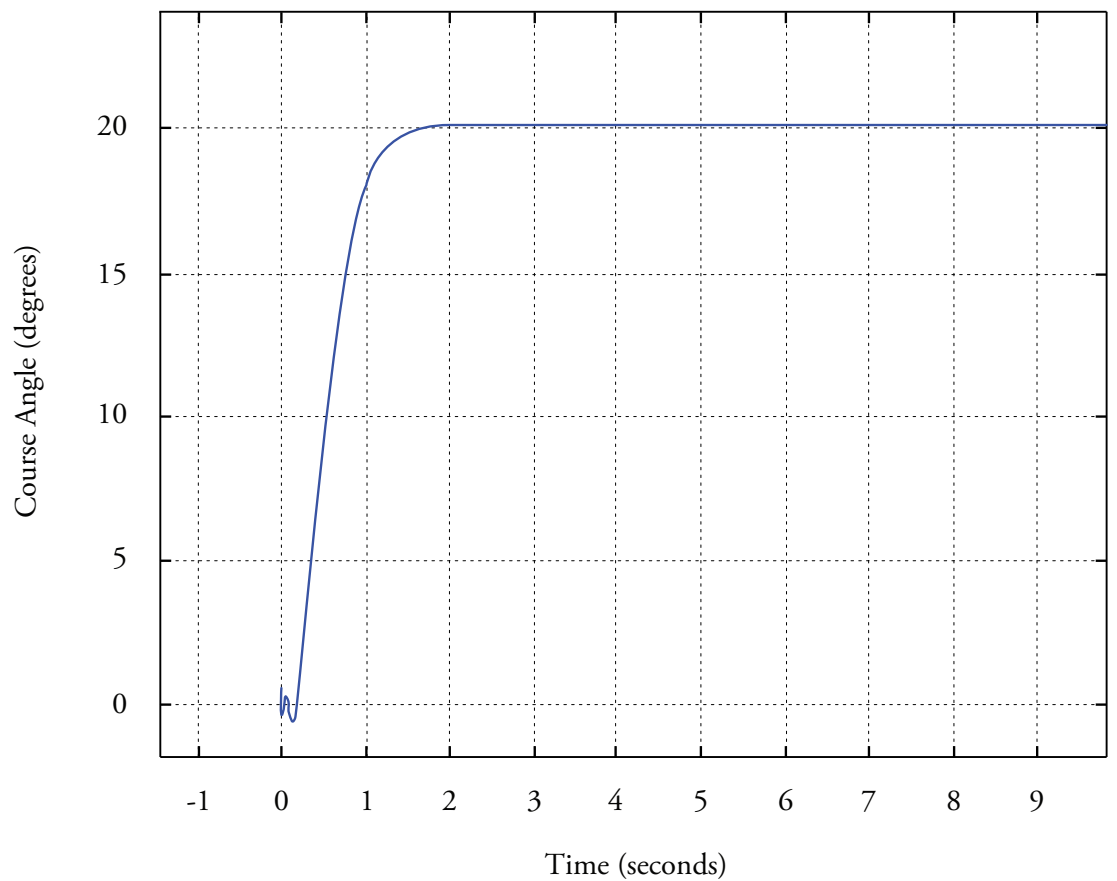

must be maintained. Hence, proceeding to size so that at high error values the controller include an adaptive fuzzy system that adjusts the action was higher than at low values, where the gain from the PI controller according to the error course must be maintained. 
Fig. 10. Real response of the controlled vehicle $(\mathrm{P}=3$ and $\mathrm{I}=8.19)$ upon course change request from $125^{\circ}$ to $305^{\circ}$

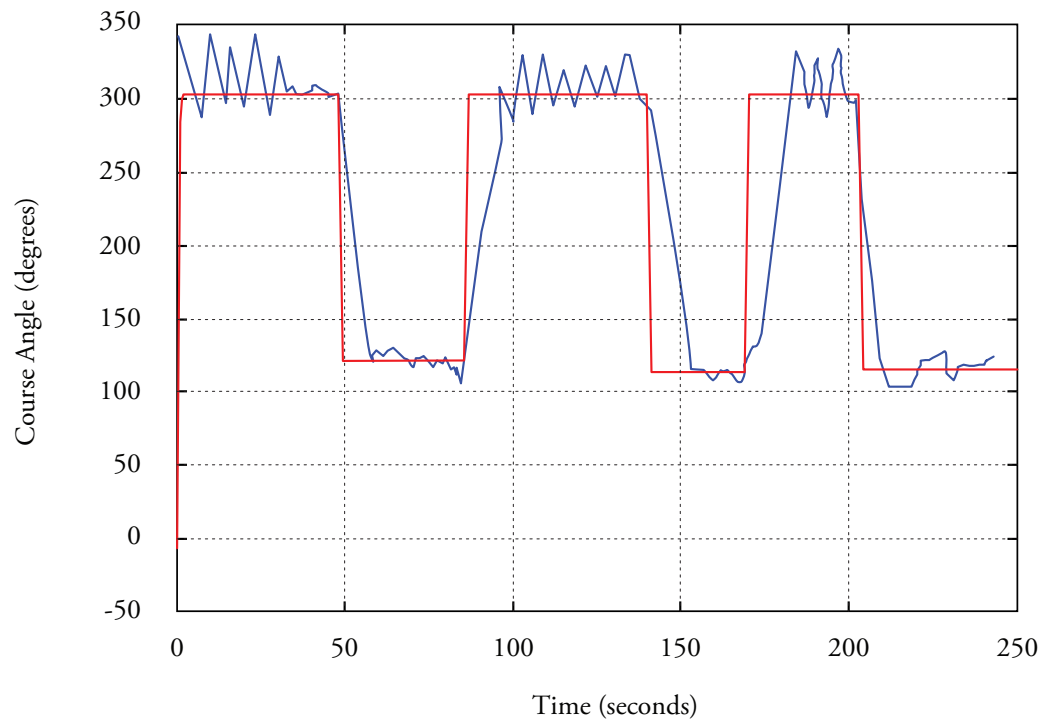

\section{Self-Tunable Fuzzy PI Controller}

Fig. 11 shows the structure of the self-tunable fuzzy PI controller:

Fig. 11. Scheme of the PI controller with fuzzy adaptation

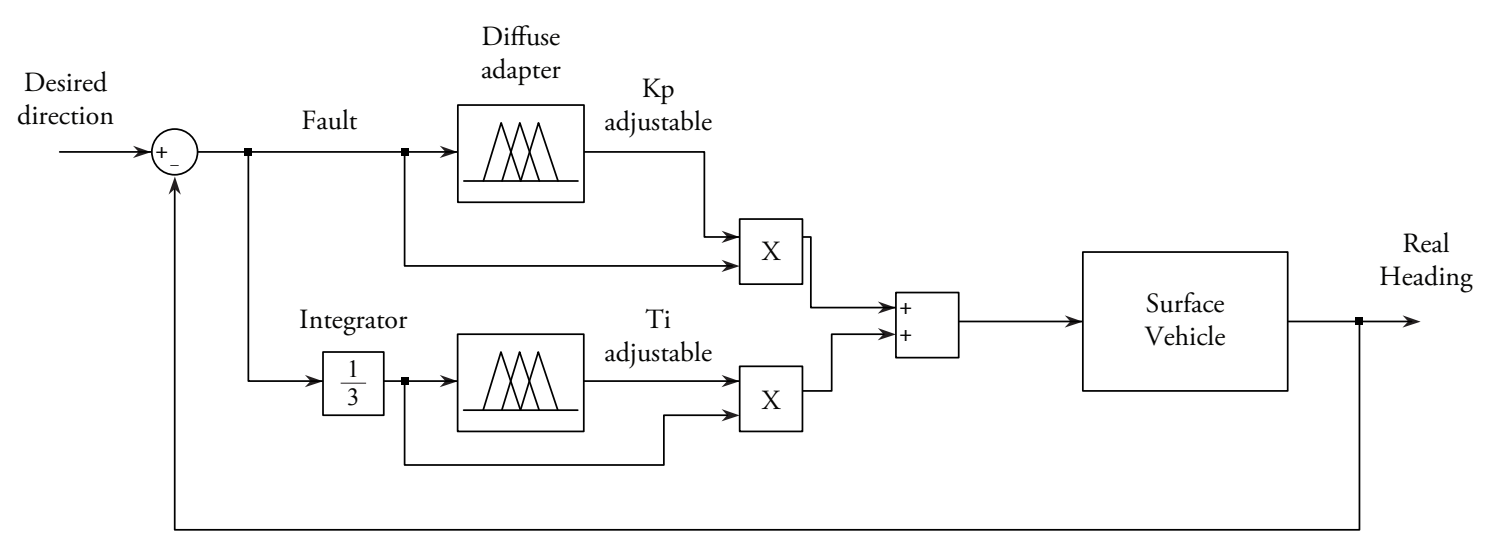

The range of the output universe of the proportional fuzzy adaptor was defined between 0.1 and 6 for the Kp generated not to bring the system to the instability zone. The range of the output universe of the integral fuzzy adaptor was defined between 1 and 100 for the Ki generated not to cause high oscillations.

The range of the error input variable was estimated between $-180^{\circ}$ and $80^{\circ}$. For both fuzzy adaptation systems, five fuzzy triangular sets were considered for the error input variable, symmetrically distributed so that the minimum values $\left(-180^{\circ}\right)$ and maximum values $\left(180^{\circ}\right)$ coincided with the modal value of the sets of two of the extremes. Likewise, three triangular sets were considered for the output variables. For each case, five fuzzy rules were considered (Table 3).

Fig. 12 shows the surface of the adaptive fuzzy system for the controller's proportional gain. 
Table 3. Fuzzy rule base

\begin{tabular}{|c|c|c|c|}
\hline Error IGain & Low & Medium & High \\
\hline Negative High & & & $\mathrm{X}$ \\
\hline Negative Medium & & $\mathrm{X}$ & \\
\hline Zero & $\mathrm{X}$ & & \\
\hline Positive Medium & & $\mathrm{X}$ & \\
\hline Positive High & & & $\mathrm{X}$ \\
\hline
\end{tabular}

It can be noted from Fig. 12 that Kp takes values according to the error value, that is, depending on how off course the vehicle is.

\section{Results}

Results of the vehicle's real response upon reference signal changes (desired course) from $305^{\circ}$ to $125^{\circ}$,

Fig. 12. Fuzzy adapter surface of the PI's proportional gain

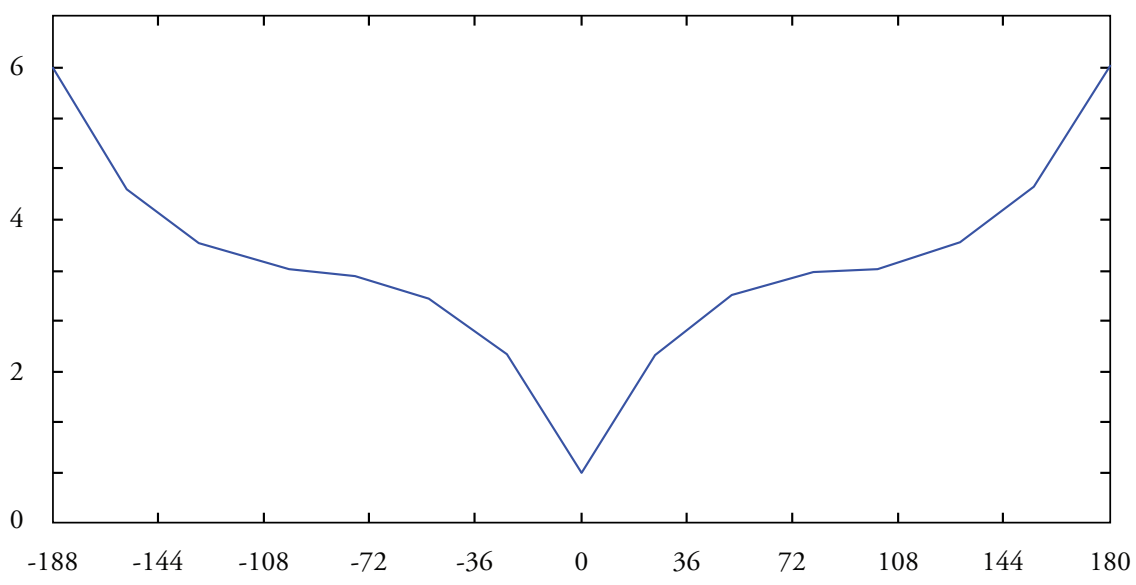

regulated with self-tunable fuzzy PI controller, are a slightly higher setting time than with the PI shown in Fig. 13. Note a response without over controller, given that $\mathrm{Kp}$ and $\mathrm{Ti}$ values diminish as impulses or significant oscillations, although with the desired response (course) is reached.

Fig. 13. Vehicle's real response self-tunable fuzzy PI controller upon course change request from $305^{\circ}$ to $125^{\circ}$

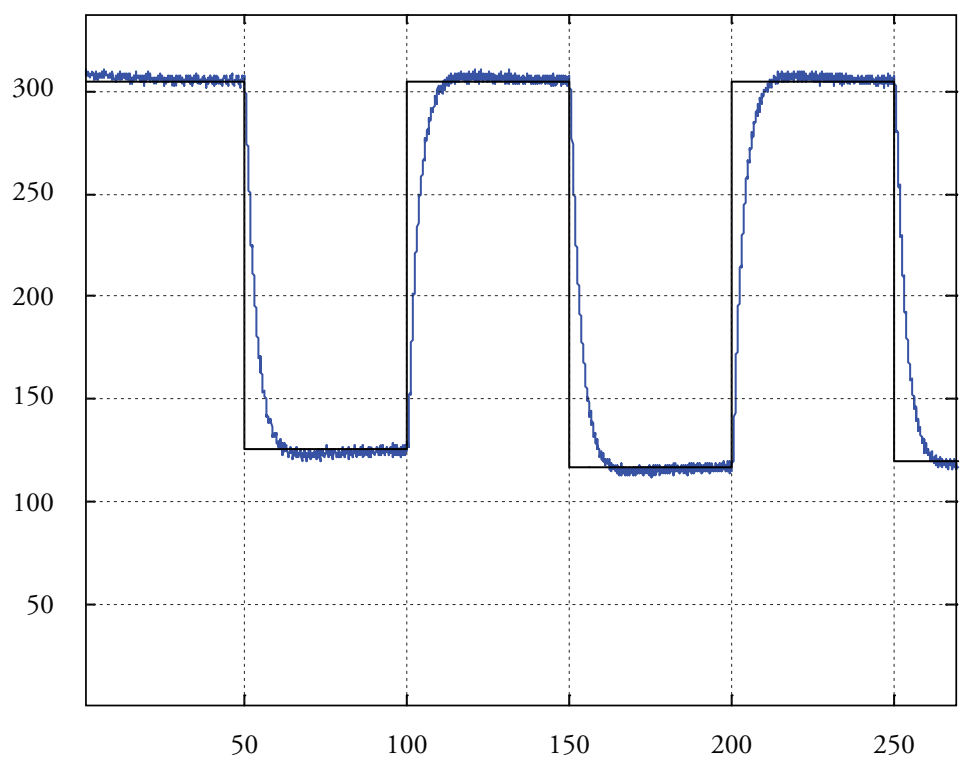




\section{Conclusions}

This work presented the identification process of a surface vehicle scale model; analysis of the temporal response from the information delivered by the root locus of the mathematical model obtained; and, with the temporal analysis proceeded to obtain the parameters of a PI controller to regulate the vehicle's change of course, employing Ziegler Nichols second method. The data obtained from the application of the PI controller in a real operation of the vehicle permitted seeing that the vehicle followed the change of course ordered, but presented high oscillations in the permanent response (maintaining the course).

A simple structure was presented of a self-tunable fuzzy PI controller in which it is only necessary to indicate the range in which the $\mathrm{Kp}$ and $\mathrm{Ti}$ parameters can vary. Thus, if the error diminishes, then the gain ( $\mathrm{Kp}$ and $\mathrm{Ti}$ ) also diminishes, considerably reducing the oscillations in stable or permanent state.

\section{References}

CHANG W-J., CHANG C-H, KU C-C. "Fuzzy controller design for Takagi-Sugeno fuzzy models with multiplicative noises via relaxed non-quadratic stability analysis". Journal of Systems and Control Engineering, Vol. 224, No. 8, pp. 918-931. December 2010.

CONTRERAS, J. "Generating fuzzy controllers for ship steering". Annual Meeting of the North American Fuzzy Information Processing Society (NAFIPS), March 2011.

CONTRERAS, J., DURÁN, F. CELI, A. "Generating Fuzzy autopilot for ship maneuvering". Ship Science \& Technology Vol. 5, No. 9, pp.: 107-114. July 2011.

DU, J., GUO, CH. "Nonlinear Adaptive Ship Course Tracking Control Based on Backstepping and Nussbaum Gain”. Proceeding of the 2004 American Control Conference Boston, Massachusetts, pp. 3845-3850, July, 2004.
FOSSEN, T. I. "Marine Control Systems. Guidance, Navigation, and Control of Ships, Rigs and Underwater Vehicles". Marine Cybernetics. Trondheim, Norway. 2002.

KRISHNA, M., RAO, S., RAJU, R., "Theoretical and experimental investigation of gain scheduling and adaptive autopilots for a model boat". International Journal of Engineering Science and Technology. Vol. 3, No. 2, pp. 902-911, 2011.

LOO, C. K., MASTORAKIS, N.E. "Particle Swarm Optimization of Fuzzy Model Reference Learning Controller for Tanker Ship Steering". Proceedings of the 11th WSEAS International Conference on Systems, Agios Nikolaos, Crete Island, Greece, July 23-25, 2007.

NGUYEN L.A., Le M.D., NGUYEN S.H., NGUYEN V.T., NGHIEM T.H. "A New and Effective Fuzzy PID Autopilot For Ships". SICE Annual Conference. Fukui, Japan. 2003.

TZENG, CH-Y., CHEN, J.F. "Fundamental Properties of Linear Ship Steering Dynamic Models", Journal of Marine Science and Technology, Vol. 7, No. 2, pp. 79-88. 1999.

VELAGIC, J., VUKIC, Z., OMERDIC, E. "Adaptive fuzzy ship autopilot for trackkeeping". Control Engineering Practice, vol. 11, pp. 433-443. 2003.

VELASCO, F.J., REVESTIDO, E., LÓPEZ, E., Moyano, E., Haro Casado, M. "Autopilot and Track-Keeping Simulation of an Autonomous In-scale Fast-ferry Model”. 12th WSEAS International Conference on Systems, Heraklion, Greece, July 22-24, 2008.

WITKOWSKA, A., SMIERZCHALSKI, R., "Nonlinear Back-stepping Ship Course Controller", R\&RATA, vol, 1, No. 2, pp. 147155. Jun. 2008. 